\title{
Early-warning Model for Tourism Sus- tainable Development Based on Grey Neural Network-Taking Lanzhou City for Example
}

\author{
Xiuping Yang ${ }^{1,2}{\text { Erchao } \mathrm{Li}^{1} \text { Gangmin Weng }}^{2}$ \\ ${ }^{1}$ College of Economy and Management, Lanzhou University of Technology, Lanzhou, \\ 730050, China \\ ${ }^{2}$ College of Economy and Management, Yanshan University, Qinhuangdao Hebei, \\ 066040, China
}

\begin{abstract}
Early-warning research of tourism sustainable development is a highly complicated problem. This paper discusses the conception of the early-warning system about tourism sustainable development. Basing on the characteristics of tourism oneself, it sets up the evaluation indicators system and building the earlywarning system about tourism sustainable development based on grey neural network. Takes Lanzhou City for an example and puts forward to some measures. Result demonstrates the speediness and efficiency of this algorithm. This algorithm shows the advantage in earlywarning research of tourism sustainable development.
\end{abstract}

Keywords: Tourism Sustainable Development, Early-warning System, Grey Neural Network

\section{Introduction}

The growth and expansion of the tourism industry in recent decades is a highly complex phenomenon whose study has to be approached using multiple disciplines. In the present economic system, quantitative growth has been positive and has served as a base for model of tourist development. The tourism environment is the basic conditions for tourism survival and sustainable development. With the development of China's tourism industry, tourism demand rapid expansion, but most of the tourist attractions in the original base is relatively weak, tourist holiday travel is relatively concentrated, and the uneven spatial distribution, resulting in problems of supply and demand, tourism activities on the negative impact of the environment has become increasingly prominent. To achieve the sustainable development of tourist destinations, domestic and foreign scholars in recent years have some research in the early warning of tourist destinations provide the basis of scientific decision-making for the scenic managers [1].There are lots of empirical knowledge in the warning theory of tourism field, there are some differences in different types of early warning indicators, and tourism activities is seasonal and random fluctuations, how to select scientific and reasonable indicators and to minimize the influence of human factors in early warning analysis is one of the urgent problem in the research of tourism sustainable development.

The early-warning model of tourism sustainable development has a high com- 
plexity and nonlinearity, while the previous model in traditional sense paid more attention to the linear research and existed large errors. There have been few practical assessments of the tourism destinations, partly because standardized, evaluative criteria have yet to be development. How to research the nonlinear in early-warning systems of the tourism sustainable development and how to apply expert knowledge to the study of the early-warning systems of tourism sustainable development need to solve urgently. At present, for highly complex nonlinear system of tourism sustainable development, intelligent algorithm can simplify the model and obtain good optimization results. To make the accuracy warning of tourism sustainable development is difficult, grey neural network is a good attempt on early-warning systems of sustainable tourism development to deal with nonlinearity and uncertainty, in reference [2]. At last, taking Lanzhou City as an example proves that the early-warning model designed is effective.

\section{Definition of Early-warning System}

Early-warning System of tourism sustainable development is measuring the situations of the present and the future in some scope and forecasts harm degree in some time and space. The system is a alarm and control system which can put forward to some solving measures and provide some countermeasures. In practice, the system serves the macro management of tourism sustainable development and is a feedback control system of tourism sustainable development in some scope. The system emphasizes the clear warning meaning, the looking for the warning source, the analyzing the warning signs, the warning degree and eliminating the hidden trouble of the complete process. A clear warning meaning is a premise and is the foundation of early research. Looking for the alert source is the analysis on the causes of the early warning. Analyzing the warning signs is correlation analysis of factors and is the basis for forecasting warning degree. The hidden troubles can be eliminated according to the warning degree and is the aim of early-warning, shown in Fig1.

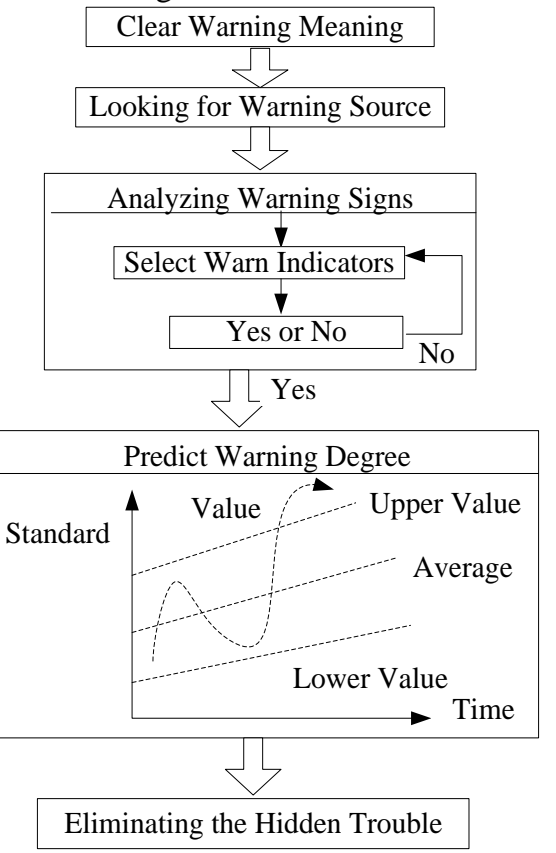

Fig. 1: Principle Chart of Tourism Sustainable Development

\section{Indicators of Early-warning System}

Due to the complexity of the tourism sustainable system, which involves many factors, the experts of domestic and foreign do not form a single authoritative definition to the tourism sustainable development. Firstly, based on system analysis and reasonable comprehensive of the selected factors that affect the tourism sustainable development, this paper uses method of experts investigate and selects warning indicators and important limiting factor of the tourism sustainable development. Secondly, this paper combines with the opinions of experts, visits and 
monitors the related early-warning indicators. Finally, removes some relatively small impact factors in traditional tourism sustainable development indicators, and complements the indicators appropriately, respectively include the natural environment system indicators $\left(F_{1}\right)$, social sup- port system indicators $\left(\mathrm{F}_{2}\right)$, economicculture system indicators $\left(\mathrm{F}_{3}\right)$, where $\mathrm{x}_{1}$, $\mathrm{x}_{2}, \cdots \cdots, \mathrm{x}_{\mathrm{n}}$ is corresponding base indicators, and this paper establishes the early-warning indicator system, shown in Table

Table1 Indicators of Early-warning System and Standardized Value

\begin{tabular}{|c|c|c|c|c|c|c|c|c|c|c|c|}
\hline & & $\mathrm{W}_{\text {eight }}$ & 2005 & 2006 & 2007 & 2008 & 2009 & 2010 & 2011 & 2012 & 2013 \\
\hline \multirow{13}{*}{$\mathrm{F}_{1}$} & $X_{1}$ & 0.0315 & 0.5873 & 0.5765 & 0.6082 & 0.6121 & 0.6009 & 0.6131 & 0.6141 & 0.6018 & 0.6107 \\
\hline & $\mathrm{X}_{2}$ & 0.0279 & 0.8031 & 0.8124 & 0.8009 & 0.8311 & 0.8162 & 0.8466 & 0.8321 & 0.8501 & 0.8642 \\
\hline & $\mathrm{X}_{3}$ & 0.0298 & 0.6107 & 0.6187 & 0.6224 & 0.6331 & 0.6256 & 0.6285 & 0.6408 & 0.6563 & 0.6621 \\
\hline & $\mathrm{X}_{4}$ & 0.0305 & 0.7214 & 0.7342 & 0.7034 & 0.7511 & 0.7448 & 0.7869 & 0.8021 & 0.8114 & 0.8620 \\
\hline & $\mathrm{X}_{5}$ & 0.0277 & 0.6932 & 0.7341 & 0.7300 & 0.7651 & 0.7835 & 0.8144 & 0.8564 & 0.8671 & 0.8812 \\
\hline & $\mathrm{X}_{6}$ & 0.0277 & 0.3003 & 0.3094 & 0.3592 & 0.3489 & 0.3843 & 0.4100 & 0.4323 & 0.5134 & 0.7124 \\
\hline & $\mathrm{X}_{7}$ & 0.0298 & 0.5021 & 0.6154 & 0.6402 & 0.6978 & 0.6849 & 0.7002 & 0.7131 & 0.8912 & 0.9124 \\
\hline & $\mathrm{X}_{8}$ & 0.0274 & 0.7004 & 0.7232 & 0.8004 & 0.8444 & 0.8432 & 0.8564 & 0.8723 & 0.8766 & 0.8943 \\
\hline & $\mathrm{X}_{9}$ & 0.0340 & 1 & 0 & 0 & 0 & 1 & 0 & 0 & 1 & 1 \\
\hline & $\mathrm{X}_{10}$ & 0.0340 & 0 & 1 & 0 & 1 & 0 & 0 & 1 & 0 & 1 \\
\hline & $\mathrm{X}_{11}$ & 0.0368 & 0 & 1 & 1 & 1 & 1 & 1 & 1 & 1 & 1 \\
\hline & $\mathrm{X}_{12}$ & 0.0298 & 1 & 1 & 1 & 1 & 1 & 1 & 1 & 1 & 1 \\
\hline & $\mathrm{X}_{13}$ & 0.0398 & 0.6316 & 0.6433 & 0.6532 & 0.6678 & 0.7153 & 0.7431 & 0.7654 & 0.7804 & 0.8065 \\
\hline \multirow{11}{*}{$\mathrm{F}_{2}$} & $\mathrm{X}_{14}$ & 0.0261 & 0.5128 & 0.5408 & 0.5718 & 0.6043 & 0.6212 & 0.6368 & 0.6514 & 0.6751 & 0.6932 \\
\hline & $\mathrm{X}_{15}$ & 0.0260 & 0.8002 & 0.8321 & 0.8453 & 0.8653 & 0.8744 & 0.8953 & 0.9066 & 0.9154 & 0.9266 \\
\hline & $\mathrm{X}_{16}$ & 0.0260 & 0.8211 & 0.8187 & 0.8301 & 0.8236 & 0.8247 & 0.8375 & 0.8489 & 0.8554 & 0.8647 \\
\hline & $X_{17}$ & 0.0230 & 0.3271 & 0.4353 & 0.4631 & 0.4735 & 0.4908 & 0.4773 & 0.4676 & 0.4886 & 0.502 \\
\hline & $\mathrm{X}_{18}$ & 0.0280 & 0.5771 & 0.5861 & 0.6001 & 0.6201 & 0.6312 & 0.6423 & 0.6401 & 0.6533 & 0.6672 \\
\hline & $\mathrm{X}_{19}$ & 0.0271 & 0.6442 & 0.6512 & 0.6623 & 0.6821 & 0.7002 & 0.7153 & 0.7306 & 0.7374 & 0.7431 \\
\hline & $\mathrm{X}_{20}$ & 0.0266 & 0.4008 & 0.4119 & 0.4231 & 0.4324 & 0.4419 & 0.4355 & 0.4001 & 0.4167 & 0.4142 \\
\hline & $X_{21}$ & 0.0245 & 0.3046 & 0.3410 & 0.3915 & 0.4250 & 0.4405 & 0.4486 & 0.4511 & 0.4615 & 0.4741 \\
\hline & $X_{22}$ & 0.0235 & 0.7714 & 0.8031 & 0.8172 & 0.8263 & 0.8351 & 0.8261 & 0.8417 & 0.8568 & 0.8644 \\
\hline & $\mathrm{X}_{23}$ & 0.0262 & 0.6055 & 0.6713 & 0.7130 & 0.6207 & 0.7067 & 0.7299 & 0.7457 & 0.7348 & 0.7555 \\
\hline & $X_{24}$ & 0.0248 & 0.7102 & 0.7209 & 0.7487 & 0.7843 & 0.8091 & 0.8011 & 0.8155 & 0.8322 & 0.8429 \\
\hline \multirow{5}{*}{$\mathrm{F}_{3}$} & $X_{25}$ & 0.0392 & 0.7636 & 0.7414 & 0.7428 & 0.7642 & 0.7527 & 0.7651 & 0.7444 & 0.7614 & 0.7706 \\
\hline & $X_{26}$ & 0.0358 & 0.7219 & 0.7316 & 0.7554 & 0.7654 & 0.7432 & 0.7853 & 0.8003 & 0.8179 & 0.8212 \\
\hline & $X_{27}$ & 0.0326 & 0.7539 & 0.7776 & 0.7962 & 0.8346 & 0.8311 & 0.8576 & 0.8641 & 0.8541 & 0.8741 \\
\hline & $\mathrm{X}_{28}$ & 0.0337 & 0.7025 & 0.7498 & 0.7152 & 0.7305 & 0.6454 & 0.7491 & 0.7641 & 0.7714 & 0.7845 \\
\hline & $X_{29}$ & 0.0338 & 0.5602 & 0.6251 & 0.6168 & 0.6329 & 0.6513 & 0.6651 & 0.6791 & 0.7111 & 0.7261 \\
\hline
\end{tabular}




\begin{tabular}{|c|c|c|c|c|c|c|c|c|c|c|c|}
\hline & $\mathrm{X}_{30}$ & 0.0357 & 0.8011 & 0.8521 & 0.8230 & 0.8314 & 0.8470 & 0.8409 & 0.8517 & 0.8702 & 0.8864 \\
\cline { 2 - 12 } & $\mathrm{X}_{31}$ & 0.0334 & 0.7274 & 0.7435 & 0.7391 & 0.7525 & 0.7718 & 0.7741 & 0.7511 & 0.7701 & 0.7841 \\
\hline & $\mathrm{X}_{32}$ & 0.0316 & 0.7674 & 0.7811 & 0.8061 & 0.8142 & 0.8207 & 0.8442 & 0.8512 & 0.8651 & 0.8701 \\
\hline & $\mathrm{X}_{33}$ & 0.0357 & 0 & 0 & 1 & 0 & 0 & 1 & 0 & 1 & 1 \\
\hline SDD & & 0.5982 & 0.6569 & 0.6688 & 0.6808 & 0.6860 & 0.7030 & 0.7075 & 0.7426 & 0.7767 \\
\hline
\end{tabular}

$* \mathrm{X}_{1}$-Total Area of Tourism Spots /Total Area of Tourism Destination; $\mathrm{X}_{2}$-Treasure Species; $\mathrm{X}_{3}$-Number of Tourists Total Area of Tourism Spots; $\mathrm{X}_{4}$-Event of Environmental Damage; $\mathrm{X}_{5}$-Water Quality Compliance Rate; $\mathrm{X}_{6}$-Air Quality Compliance Rate; $\mathrm{X}_{7}$ - Number of Garbage/Number of Tourists; $\mathrm{X}_{8}$-Significant Pollution Accident; $\mathrm{X}_{9}$-Whether or not the Integrity of the Tourism and Environment Plan; $\mathrm{X}_{10}$-Whether or not has the Impact Evaluate of the Environment for a New Tourism Plan; $X_{11}$-Whether or not has the Environment Control; $X_{12}$-Whether or not has Environment Education; $X_{13}$-Environmental Protection Measures; $X_{14}$-Bed Number; $X_{15}$-Power Supply Capacity; $X_{16}$-Water Supply Capacity; $\mathrm{X}_{17}$-Road Length of Motorcar; $\mathrm{X}_{18}$-Number of Tourists/ Number of Bed; $\mathrm{X}_{19}$-Power Consumption of Per Tourists; $\mathrm{X}_{20}$-Water Consumption of Per Tourists; $\mathrm{X}_{21}$-Sewage Water Handle Capacity; $\mathrm{X}_{22}$-Garbage Handle Capacity; $\mathrm{X}_{23}$-Usage Rate of Bed; $\mathrm{X}_{24}$-Tourism Facility of New Building Per Year; $\mathrm{X}_{25^{-}}$-Tourism Revenue/Total Revenue; $\mathrm{X}_{26}$ Number of Tourism Employment; $\mathrm{X}_{27}$-Number of Tourism Employment; $\mathrm{X}_{28^{-}}$-Tourism Revenue/Total Revenue; $\mathrm{X}_{29^{-}}$ Tourist Number/The Local Resident Population; $X_{30}$-Tourist Cost; $\mathrm{X}_{31}$-Conflict with Local Resident; $\mathrm{X}_{32}$-Number of Tourism Safe Accident; $\mathrm{X}_{33}$-Whether or not has Culture Building Plan; SDD-Sustainable Development Degree.

The indicators not only the quantity, but also have different properties. This paper must standardize the datum. The standardized indicators $\mathrm{C}_{\mathrm{i}}$ is shown in (1) and (2) about the positive and negative indicators respectively. Si is value of the average or standard. $\mathrm{Xi}$ is the value at present of some indicators. Some indicators are non numerical form. This paper describes the indicators $\mathrm{Y}_{\mathrm{ij}}$ according to 0-1 distribution, as in (3).

$$
\begin{gathered}
C_{i}=\frac{X_{i}}{S_{i}} \text { (1); } \quad C_{i}=\frac{S_{i}}{X_{i}} \\
X_{i j}=\left\{\begin{array}{lll}
0 & Y_{i j}=N(N O) \\
1 & Y_{i j}=Y & (\text { Yes })
\end{array}\right.
\end{gathered}
$$

\section{Methodology}

Base indicators $\left\{\mathrm{x}_{1}, \mathrm{x}_{2}, \cdots \cdots, \mathrm{x}_{33}\right\}$ in the early warning system is denoted by $x_{n}(t)$,where $n \in[1,33], \mathrm{t}$ denotes the time, so select the value of the k-based indicators can constitute the $n \times k$ dimension feature state space:

$$
\left[\begin{array}{cccc}
x_{1}(1) & x_{1}(2) & \cdots & x_{1}(k) \\
x_{2}(1) & x_{2}(2) & \cdots & x_{2}(k) \\
\vdots & \vdots & \vdots & \vdots \\
x_{n}(1) & x_{2}(2) & \cdots & x_{n}(k)
\end{array}\right]
$$

Gray prediction model $\operatorname{GM}(1,1)$ is used for a single time series prediction which can not reflect the variable interaction, the gray $\operatorname{GM}(1, n)$ model can describe the relationship between the variables, but generally not used for prediction. To establish the $\operatorname{GM}(1,1)$ gray model for all indicators in the early warning system:

$$
\frac{d x^{(1)}{ }_{i}}{d t}+a_{i} x_{i}^{(1)}=u_{i}
$$

Finally obtain the prediction results

$$
\begin{aligned}
& x_{i}^{(1)}(k+1)=\left[x_{i}^{(0)}(1)-\frac{u_{i}}{a_{i}}\right] e^{-a_{i} k}+\frac{u_{i}}{a_{i}} \\
& \hat{x}_{i}^{(0)}(k+1)=x_{i}^{(1)}(k+1)-x_{i}^{(1)}(k)
\end{aligned}
$$

Posteriori estimation is used to test the prediction accuracy, assuming $\varepsilon_{i}^{(0)}(k+1)$ is the residual error for predictive value and the true value of the, then obtain

$$
\varepsilon_{i}^{(0)}(k+1)=x_{i}^{(0)}(k+1)-\hat{x}_{i}^{(0)}(k+1)
$$

After $\operatorname{GM}(1,1)$ gray prediction model is used to predict based on indicators in the early warning system, we can obtain the basic trend of the base indicators, but the errors need to reduce. As the prediction error exists in the residuals between the true value and the predictive value with the base indicators, in this paper, grey neural network is used to amend the 
GM $(1,1)$ model prediction. The neural network training processes see Reference.

Use the $\mathrm{m}$ training samples, which $\varepsilon_{i}^{(0)}(k-1), \varepsilon_{i}^{(0)}(k-2), \cdots, \varepsilon_{i}^{(0)}(k-m)$ is the input of grey neural network and $\varepsilon_{i}^{(0)}(k)$ is the output of grey neural network. Gradient descent method is adopted to adjust grey neural network weights, obtain the predictive value $\hat{\varepsilon}_{i}^{(0)}(k+1)$ based on the early warning system indicators residuals $\varepsilon_{i}^{(0)}(k+1)$. The ultimate predictive value of the base indicators is

$$
x_{i}^{(0)}(k+1)=\hat{x}_{i}^{(0)}(k+1)+\hat{\varepsilon}_{i}^{(0)}(k+1)
$$

\section{Evaluate}

According to the different levels of sustainable development degree, set the warning interval SDD. SDD can be divided weaker sustainable development $\left(\mathrm{S}_{1}\right)$, weak sustainable development $\left(\mathrm{S}_{2}\right)$, basically sustainable development $\left(\mathrm{S}_{3}\right)$, more sustainable development $\left(\mathrm{S}_{4}\right)$ and the most sustainable development $\left(\mathrm{S}_{5}\right)$, as shown in Table 2 .

Table 2 The Warning Signal Table of Tourism Sustainable Development Degree

\begin{tabular}{|c|c|c|c|c|c|}
\hline SDD & {$[0,0.20)$} & {$[0.20,0.40)$} & {$[0.40,0.60)$} & {$[0.60,0.80)$} & {$[0.80,1.0]$} \\
\hline level & $\begin{array}{c}\text { weaker } \\
\text { sustainable } \\
\text { development }\end{array}$ & $\begin{array}{c}\text { weak } \\
\text { sustainable } \\
\text { development }\end{array}$ & $\begin{array}{c}\text { basically } \\
\text { sustainable } \\
\text { development }\end{array}$ & $\begin{array}{c}\text { more } \\
\text { sustainable } \\
\text { development }\end{array}$ & $\begin{array}{c}\text { most } \\
\text { sustainable } \\
\text { development }\end{array}$ \\
\hline
\end{tabular}

\section{Empirical Research}

Lanzhou, capital of Gansu Province, is a major stop on the ancient "Silk Road" west of Xi'an. Situated on the upper reaches of the Yellow River, Lanzhou has been important for thousands of years because of the Hexi Corridor, or "Corridor West of the Yellow River," in which early Chinese civilization began. About 3000 years ago, in the Zhou Dynasty, agriculture began to take shape in the basins of the Jin and Wei Rivers that formed the corridor, marking the beginning of the great Yellow River basin civilization. Lanzhou became capital of a succession of tribal states during the turbulent ventures that followed the decline of the Han Dynasty. During this time of turmoil, people began to turn to ideologies that satisfied their need for hope. Taoism developed into a religion, and Buddhism became the official religion in some of the northern states. Buddhist art also flourished, and shrines were built in tem- ples, caves, and on cliffs. From the fifth to the 11th centuries, Dunhuang, beyond the Yumen Pass of the Great Wall, became a center for Buddhist study, drawing scholars and pilgrims from afar. It was a period in which magnificent works of art were created. In this paper, specific input data collected are based on the Survey Method and the weight $(\mathrm{W})$ is design by AHP, shown in Table 1.Combine the comprehensive judgment of experts, monitoring levels S. According to base indicators data in Table 1 of the 2005 to 2012, gray forecasting and neural network residual compensation, we can find the prediction value is 0.7767 in 2013 , concludes that the more sustainable development.

\section{Conclusion}

Early-warning system of tourism sustainable development is a highly complex nonlinear system and it is very difficult to establish a precise mathematical model. In this paper, the fuzzy reasoning method 
and grey neural network is adopted to deal with this system. Lanzhou City as an example proves that the early-warning model designed is feasible and effective.

\section{Acknowledgements}

This article is funded by the general project of the Ministry of Education, Humanities and Social Sciences (Western and Frontier Areas Projects) (11XJC630016), The Youth Foundation of National(10CGL046), Gansu Province Natural Science Fund Project(1112RJZA010) and Training Program at the Lanzhou University of Tech- nology HongLiu Young Teachers(Q201213)and (Q201210).

\section{References}

[1] Liu Jia,Liu Ning, Yang Kun. A Review of Tourism Environment Carrying Capacity Warning [J]. Journal of Ocean University of China(Social Sciences),2012,1:73-77

[2] Yang Xiuping,Weng Gangmin. Research of Early-warning System about Tourism Sustainable Development Based on Chaotic GREY Neural Network [J]. Future and Development,2011,4: 25-28 